Original article

\title{
EFFECT OF PROBIOTICS ON DOXYCYCLINE DISPOSITION IN GASTRO-INTESTINAL TRACT OF POULTRY
}

\section{PAVLOVA}

Department of Pharmacology, Veterinary Physiology and Physiological Chemistry, Faculty of Veterinary Medicine, Trakia University, Stara Zagora, Bulgaria

\section{Summary}

Pavlova, I., 2015. Effect of probiotics on doxycycline disposition in gastro-intestinal tract of poultry. Bulg. J. Vet. Med., 18, No 3, 248-257.

Poultry feed is often supplemented with probiotics in order to improve disease resistance and growth performance and to decrease undesirable effects of antibacterial therapy. Therefore this study was designed to evaluate the effect of probiotics such as Lactobacillus brevis, L. plantarum and L. bulgaricus on pharmacokinetics of doxycycline in healthy DUC broiler chickens. The treatment with doxycycline at a dose of $10 \mathrm{mg} / \mathrm{kg}$ body weight started on the $15^{\text {th }}$ day after hatching for 5 days via drinking water. The probiotics treated group received Lactobacillus strains for 15 days, 5 days after hatching. Treatment with probiotics did not lead to statistically significant differences in serum concentrations of doxycycline between both groups of chickens. The value of $\mathrm{C}_{\max }$ was significantly higher in the liver of doxycycline + probiotics treated chickens $(0.23 \pm 0.1 \mu \mathrm{g} / \mathrm{g})$ than in doxycycline-treated group $(0.19 \pm 0.17 \mu \mathrm{g} / \mathrm{g})$. The same tendency was observed in the jejunum of both groups of animals suggesting favourable results in the cure of bacterial diseases of the gastrointestinal tract of poultry.The selected dose was appropriate for treatment of infections caused by pathogens with MIC < $0.25 \mu \mathrm{g} / \mathrm{mL}$ irrespective of antibiotic administration alone or in combination with probiotics. The simultaneous treatment of chickens with probiotics and doxycycline did not entail changes in the dose regime of the antibiotic.

Key words: chicken, doxycycline, pharmacokinetics, probiotics

\section{INTRODUCTION}

The increasing antimicrobial resistance in livestock and poultry becomes a serious problem worldwide. Therefore alternatives to improve disease resistance and growth performance in high intensity food animal production are required. Nowadays, the combination of solutions such as strict disinfection in and around the poul- try house, food and water quality improvement and vaccination are employed to achieve high performance in poultry industry (Doyle \& Erickson, 2006). Nutritional strategies and some feed additives such as organic acids, acidifiers, probiotics, oligosaccharides, herbs and essential oils were used as alternatives to antibio- 
tics to ensure gut health and enteric disease resistance (Denli et al., 2003; Ferket, 2004). Probiotics are widely applied as feed additives in poultry farming due to proven health benefit to the host. Probiotics as lactobacilli, positively modulate the host immunity (Huang et al., 2004; Apata, 2008). Their beneficial effects on gastrointestinal disturbances are attributed to the production of antimicrobial substances such as lactic acid and bacteriocins, competitive adherence of probiotic strains to the intestinal mucosa, which prevents colonisation by pathogens, strengthening of the gut epithelial barrier and modification of the gut microbiota. The efficacy of probiotics depends on factors including microbial species composition (e.g., single or multiple strains) and viability, application method and frequency, administration level, diet composition, bird age and environmental stress factors (Mountzouris et al., 2010). Many probiotic strains such as Lactobacillus spp., Streptococcus spp., Bifidobacterium and Bacillus spp. used in poultry have resulted in higher body weight gain, better feed conversion and reduced mortality (Edens, 2003; Griggs \& Jacobs, 2005; Kabir, 2009; Santini et al., 2010). The superior effect of fermented probiotics on growth performance of broiler chickens was proven and according to the results, probiotics were recommended for routine use in the poultry feed (Ashayerizadeh et al., 2014).

The gut microbiota is now recognised to exert an important influence on the absorption and pharmacokinetics of many compounds. Probiotics, through its modulation, can play a role in changes of drug pharmacokinetics (Stojancevic et al., 2013). Despite their advantages, probiotics are not a universal alternative to antibiotics. In some bacterial diseases they are used simultaneously with drugs, including antibiotics. Tetracyclines are widely used in poultry as prophylactic and therapeutic agents. Doxycycline is a semi-synthetic, bacteriostatic and a broad spectrum antibiotic with pharmacokinetic properties superior to those of older tetracyclines: higher lipid solubility, complete absorption, better tissue distribution, longer elimination half-life and lower affinity for calcium. Many of these pharmacokinetic characteristics have been studied in detail, mainly in humans but also in animals (Cars \& Ryan, 1988). A few pharmacokinetic studies have been done in chickens (Anadon et al., 1994). Animal studies showed that administration of chlortetracycline and probiotics in the feed improved pig performance but did not show any pharmacokinetic interaction with probiotics (Choi et al., 2011). Mechanisms of action of probiotics, as well as interactions with antibiotics, the host and the gastro-intestinal microbiota are not completely understood (Modesto et al., 2009). Previous studies elucidated drug-drug pharmacokinetic interactions of flunixin meglumine (Yang et al., 2012), diclazuril, halofuginone (El-Gendi et al., 2010), mycotoxins (Atef et al., 2002) and doxycycline in broilers but there is lack of information about the effect of probiotics on the disposition of this antibacterial agent.

Therefore, the aim of the present study was to investigate the pharmacokinetics of doxycycline, administered alone or in combination with probiotics in DUC broiler chickens.

\section{MATERIALS AND METHODS}

\section{Drug}

Doxycycline hyclate (Doxy-200 ws, Interchemie, Venray, Holland) was used for treatment. 
Doxycycline hyclate $\geq 98 \% \quad$ (TLC) Lot\# BCBF9827V (Sigma) and Oxytetracycline hydrochloride $\geq 95 \% \quad$ (HPLC grade) Lot\# BCBG9599V (Sigma) were used as internal standards during the HPLC analysis.

\section{Probiotics}

Lactobacillus brevis, L. plantarum and L. bulgaricus (a laboratory collection of The Stephan Angeloff Institute of Microbiology, BAS, Bulgaria) were pre-selected as candidate-probiotic strains (Danova et al., 2012). They were cultured overnight in skimmed milk (Humana, Germany), lyophilised and stored at $-20{ }^{\circ} \mathrm{C}$ until the experiments. The lyophilised samples of L. brevis $\left(1.6 \times 10^{6} \mathrm{CFU} / \mathrm{mg}\right.$ lyophilised product), L. plantarum $\left(1.06 \times 10^{6} \mathrm{CFU} / \mathrm{mg}\right)$ and L. bulgaricus $\left(0.25 \times 10^{3} \mathrm{CFU} / \mathrm{mg}\right.$ product) were used. The strains were resistant to doxycycline.

\section{Animals and husbandry}

One hundred one-day-old DUC chickens were taken from a commercial hatchery. The birds were placed, according to the species requirements in the animal house of the Department of Pharmacology. Clinical signs of disease were not observed during the trial. In the animal house, a room temperature $26-28{ }^{\circ} \mathrm{C}$ and 24 hours lighting were maintained. Water and food (broiler starter withoutany drugs) were supplied ad libitum. The experimental procedure was approved by the Ethical Committee at Trakia University, Stara Zagora (Reference No 65/18.10.2013).

\section{Experimental design}

The chickens were allocated in two groups: Group I ( $\mathrm{n}=48)$ received doxycycline and Group II $(n=48)$ was treated with probiotics and doxycycline. The other 4 chickens were untreated and were used for obtaining control serum and tissue samples. Probiotics were administered on the $5^{\text {th }}$ day after hatching for 15 days via feed at a dose rate of $1 \mathrm{~g}$ of each probiotic strain $/ \mathrm{kg}$ feed. They were daily added to the feed which was stored at $-20{ }^{\circ} \mathrm{C}$ until delivery to the chickens. The treatment with doxycycline started 15 days after hatching and lasted for 5 consecutive days. The antibacterial drug was administered via drinking water at a dose of $10 \mathrm{mg} / \mathrm{kg}$ body weight. Each day, the solutions in drinking water were freshly prepared between 7.30 and $8 \mathrm{~h}$ in the morning and between 16 and $17 \mathrm{~h}$ in the afternoon. Blood samples (each of $0.7 \mathrm{~mL}$ ) were taken $2,3,4,6,9,12,15$, 24, 122, 124, 126, 129 and 144 hours after the start of drug administration from the brachial vein of chickens from both groups. They were collected from six animals from each group and at each time interval so that no more than $0.7 \mathrm{~mL}$ blood was taken per chicken during the sampling. Serum was separated after centrifugation of blood samples at $1800 \times g$ for 15 min and was stored at $-70{ }^{\circ} \mathrm{C}$ until analysis. Tissue samples (from liver, duodenum and jejunum) were collected on hours 122, 124, 126, 129 and 144 after the beginning of the treatment. Six animals from each group were euthanised at each time interval. Tissue samples were stored at $-70{ }^{\circ} \mathrm{C}$.

\section{Drug analysis}

Doxycycline concentrations were analysed by high-performance liquid chromatograph (HPLC) coupled with PDA detector (Baert et al., 2000). Shortly, $15 \mu \mathrm{L}$ of the internal standard $(11 \mu \mathrm{g} / \mathrm{mL}$ oxytertacycline) and $19.5 \mu \mathrm{L}$ trifluoroacetic acid were added to $150 \mu \mathrm{L}$ of serum samples. After vortexing, the samples were centrifuged for $10 \mathrm{~min}$ at $10800 \times \mathrm{g}$ at $22{ }^{\circ} \mathrm{C}$. 
The supernatants were transfered to HPLC vials and $20 \mu \mathrm{L}$ were injected into the HPLC system (Thermo Fisher Scientific Inc., USA) (Laczay et al., 2001). The standard solutions of doxycycline were prepared in serum from untreated animals at concentrations of $20,10,5,2.5,1,0.5$, 0.25 and $0.125 \mu \mathrm{g} / \mathrm{mL}$. They were processed according to the described procedure.

The tissue samples ( $1 \mathrm{~g})$ were homogenised in $0.5 \mathrm{~mL}$ oxalate buffer and 100 $\mu \mathrm{L}$ inner standard. After vortexing, $5 \mathrm{~mL}$ $0.4 \mathrm{M}$ oxalate buffer were added to each sample, left to stand $15 \mathrm{~min}$ and centrifuged for $15 \mathrm{~min}$ at $4000 \times \mathrm{g}$. The supernatants were decanted into clean tubes and the residues were reextracted twice. After filtration, the supernatants were applied to SPE cartriges (BAKERBOND SPE Column C18 $200 \mathrm{mg} / 3 \mathrm{~mL}$; Lot No. 1308100010) preconditioned with $2 \mathrm{~mL}$ methanol and $2 \mathrm{~mL}$ water. Elution was performed with a mixture of methanol/acetonitrile/0.01M oxalic acid according to Nikolaidou et al. (2008). The eluents were evaporated to dryness at $40{ }^{\circ} \mathrm{C}$ and the dry residues were reconstituted in $100 \mu \mathrm{L}$ of methanol; then $20 \mu \mathrm{L}$ were injected into the HPLC system (Nikolaidou et al., 2008). Standard curves were prepared with tissue samples from untreated animals and solutions of doxycycline with concentration $20,10,5,2.5$ and $1 \mu \mathrm{g} / \mathrm{mL}$.

\section{Pharmacokinetic analysis}

Pharmacokinetic parameters were calculated with Phoenix 6.0 software (Pharsight Corporation, Mountain View, CA, USA) using non-compartmental analysis and one-compartmental analysis with absorption after naive pooling of serum drug concentrations. Pharmacokinetic parameters with non-compartmental analysis were estimated with sparse sampling op- tion. Naive pooling was done by using all individual data. Pharmacokinetic parameters for serum were first calculated on the basis of mean serum concentrations for each sampling time. In addition, the subject information was used to calculate standard errors that account for any correlations in the data, resulting from repeated sampling of individual animals. Standard error of the mean $\mathrm{C}_{\max }$ was calculated as the sample standard deviation of the $y$ values at time $T_{\max }$ divided by the square root of the number of observations at $T_{\max }$, or equivalently, the sample standard error of the $\mathrm{y}$-values at $\mathrm{T}_{\max }$. AUC was calculated by the linear trapezoidal rule. Noncompartmental model was applied for analysis of tissue concentrations. The major pharmacokinetic/pharmacodynamic (PK/PD) index determining doxycycline's in vivo efficacy is the time of serum concentration exceeding the MIC (minimal inhibitory concentration) ( $\mathrm{T}>\mathrm{MIC}$ ) (Toutain et al., 2002). It was calculated on the basis of MIC value of doxycycline in broth $-0.25 \mu \mathrm{g} / \mathrm{mL}$ and serum $-1 \mu \mathrm{g} / \mathrm{mL}$ for the pathogenic strain $E$. coli $\mathrm{O} 78 / \mathrm{H} 12$. MIC values were determined according to Clinical and Laboratory Standards Institute, (2008).

\section{Statistical analysis}

Statistical analysis was performed with Mann-Whitney test (Prism 4.0 software). Level of significance was set at $\mathrm{P}<0.05$.

\section{RESULTS}

Pharmacokinetic parameters were calculated with one-compartmental analysis and non-compartmental analysis of sparse data in order to characterise absorption and elimination phases. The differences in serum levels between both groups of chickens were not statistically significant 
(Table 1, Fig. 1). The non-compartmental analysis of sparse data showed statistically insignificant differences in the values of $\mathrm{T}_{\max }, \mathrm{C}_{\max }, \mathrm{C}_{\min }$ and $\mathrm{C}_{\text {avg }}$ with higher fluctuations in the doxycycline treated group in comparison to doxycycline + probiotics treated chickens. The accumulation index was 1.08 for the animals that received doxycycline and probiotics and 1.28 for the group treated with doxycycline only. These values showed that there were no indices for accumulation of the drug in this animal species.

The value of $\mathrm{C}_{\max }$ was significantly higher in the liver of doxycycline+ probiotics treated chickens $(0.23 \pm 0.1 \mu \mathrm{g} / \mathrm{g}$ at 122 $\mathrm{h}$ and $0.218 \pm 0.06 \mu \mathrm{g} / \mathrm{g}$ at $124 \mathrm{~h})$ than in the doxycycline-treated group $(0.19 \pm 0.17$ $\mu \mathrm{g} / \mathrm{g}$ at $122 \mathrm{~h}$; not determined at $124 \mathrm{~h}$ ). The same tendency was observed in the jejunum of both groups of animals $0.05 \pm 0.01 \mu \mathrm{g} / \mathrm{g}$ and $0.03 \pm 0.0 \mu \mathrm{g} / \mathrm{g}$, respectively. Similar values were obtained in the duodenum $(0.20 \pm 0.05 \mu \mathrm{g} / \mathrm{g}$ and $0.22 \pm 0.04 \mu \mathrm{g} / \mathrm{g}$, respectively).

Our results showed that pharmacokinetic-pharmacodynamic indices in both groups were similar. Assuming a MIC value of $0.25 \mu \mathrm{g} / \mathrm{mL}, \mathrm{T}>\mathrm{MIC}$ was over $80 \%$ for the whole time of the treatment. The antibiotic concentrations during the 5-day treatment were higher than serum MIC value (Fig. 1).

\section{DISCUSSION}

Antimicrobial therapy is an important tool in reducing both the incidence of infectious diseases and mortality in poultry husbandry. Although few pharmacokinetic studies have been done in chickens after prolonged administration via drinking water, doxycycline is often used to treat avian infectious diseases such as colibacillosis, pasteurellosis, mycoplasmosis and chlamydiosis (Butaye et al., 1997; Semjen

Table 1. Pharmacokinetic parameters $(m e a n \pm S D)$ of doxycycline in serum of broiler chickens after oral treatment for 5 consecutive days at a dose of $10 \mathrm{mg} / \mathrm{kg}$, administered with and without probiotics

\begin{tabular}{llcc}
\hline Parameters & Units & Doxycycline & Doxycycline+probiotics \\
\hline \multicolumn{2}{l}{ One-compartmental analysis, p.o. } & & \\
$\mathrm{K}_{\mathrm{ab}}$ & $\mathrm{h}^{-1}$ & $0.14 \pm 0.10$ & $0.17 \pm 0.18$ \\
$\mathrm{~K}_{\mathrm{el}}$ & $\mathrm{h}^{-1}$ & $0.09 \pm 0.03$ & $0.08 \pm 0.03$ \\
$\mathrm{AUC}_{0 \rightarrow \infty}$ & $\mathrm{h} . \mu \mathrm{g} / \mathrm{mL}$ & $57.59 \pm 16.24$ & $57.87 \pm 4.33$ \\
$\mathrm{~T}_{1 / 2 \mathrm{abs}}$ & $\mathrm{h}$ & $6.48 \pm 2.41$ & $6.50 \pm 2.61$ \\
$\mathrm{~T}_{1 / 2 \beta}$ & $\mathrm{h}$ & $7.27 \pm 1.19$ & $7.56 \pm 0.57$ \\
$\mathrm{~T}_{\max }$ & $\mathrm{h}$ & $10.18 \pm 1.76$ & $10.05 \pm 2.22$ \\
$\mathrm{C}_{\max }$ & $\mu \mathrm{g} / \mathrm{mL}$ & $1.80 \pm 0.28$ & $1.86 \pm 0.29$ \\
\hline Non-compartmental analysis, p.o. & & \\
$\mathrm{T}_{\max }$ & $\mathrm{h}$ & 9 & 12 \\
$\mathrm{C}_{\max }$ & $\mu \mathrm{g} / \mathrm{mL}$ & 2.07 & 2.00 \\
$\mathrm{C}_{\min }$ & $\mu \mathrm{g} / \mathrm{mL}$ & 0.64 & 0.57 \\
$\mathrm{C}_{\mathrm{avg}}$ & $\mu \mathrm{g} / \mathrm{mL}$ & 1.40 & 1.48 \\
\hline
\end{tabular}

$\mathrm{K}_{\mathrm{ab}}$ - absorption rate constant; $\mathrm{K}_{\mathrm{el}}$ - elimination rate constant; $\mathrm{AUC}_{0 \rightarrow \infty}-$ area under the concentration-time curves; $\mathrm{T}_{1 / 2 \beta}$ - elimination half-life; $\mathrm{T}_{1 / 2 \text { abs }}-$ absorption half-life; $\mathrm{C}_{\max }-$ maximum serum levels; $\mathrm{T}_{\max }-$ time of $\mathrm{C}_{\max } ; \mathrm{C}_{\min }-$ minimum serum levels; $\mathrm{C}_{\mathrm{avg}}$ - average serum levels. 


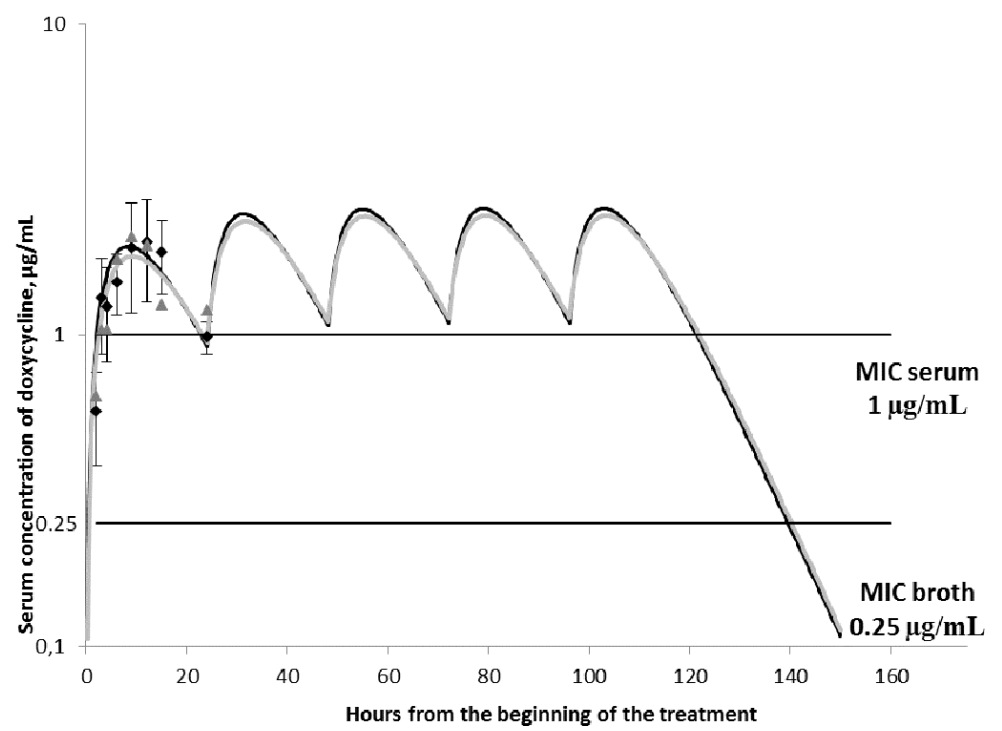

Fig. 1. Predicted (lines) and observed (dots) serum concentrations during the 5-day oral treatment with doxycycline via drinking water at a dose of $10 \mathrm{mg} / \mathrm{kg}$ in broiler chickens; $\boldsymbol{\Delta}$ and the gray line: antibiotic concentrations in doxycycline-treated group; and the black line: antibiotic concentrations in doxycycline+ probiotics-treated group.

et al., 1998; Burch \& Valks, 2002). The use of doxycycline for the treatment of experimentally induced colibacillosis in broilers through the drinking water was evaluated as effective (Akbar et al., 2009). Doxycycline at a dose of $10 \mathrm{mg} / \mathrm{kg}$, administered for five days resulted in a complete clinical and bacteriological healing of the broilers with colisepticemia (Cristina et al., 2010). In poultry farming, antibiotics may be administered through feed or drinking water to whole flocks rather than to individual animals. This fact may contribute for increasing the emergence of resistant bacteria due to unequal administration of the drug in the flock which could be a risk for public health (Miranda et al., 2008). Hence, it is important to optimise dosing regimen of antibiotics when they are used in combination with other drugs or additives in order to maintain efficacy and reduce selection of resistance. Therefore in our study we in- vestigated the effect of probiotics such as Lactobacillus spp. on pharmacokinetics of doxycycline. Despite probiotics are routinely used in poultry husbandry, the effect of their administration on doxycycline disposition pharmacokinetics has not been described.

The results from the current study showed that pharmacokinetics of doxycycline in three weeks old DUC broiler chickens was similar to published data (Espigol et al., 1997). The higher values of $\mathrm{C}_{\max }(5.36 \pm 0.26 \mu \mathrm{g} / \mathrm{mL})$ and $\mathrm{T}_{\max }$ $(3.60 \pm 0.26 \mu \mathrm{g} / \mathrm{mL})$ were obtained by Hantash et al. (2008) after administration of a single oral dose. The differences can be explained by the route of drug administration, which in our experiment resulted in slower rate and lesser extent of absorption Previous studies with probiotic Lactobacillus strains, administered in the feed of broilers indicated that morphology of duodenum was significantly changed by 
increasing the length of villi and crypt depth (Sharifi et al., 2012). It is well known that lactobacilli have low activities of metabolizing enzymes, produce organic acids with a resulting decrease in $\mathrm{pH}$ of the intestines, increase the expression of tight junction proteins and as a result, strengthen the gut epithelial barrier (Stojancevic et al., 2013). However, the possible effect of these changes on doxycycline absorption has not been studied. In our experiments, doxycycline disposition was not significantly altered by the probiotics treatment. Significantly higher concentrations of doxycycline in the liver and intestinal tissues in probiotic-treated group in comparison to the chickens, treated with the antibacterial drug only, indicated that probiotics did not modulate the disposition of doxycycline in the intestines and increased antibacterial concentrations in the liver - a prerequisite for successful treatment of gastro-intestinal infections in broilers.

Doxycycline possess a bacteriostatic activity. Last decade the pharmacokinetic/ pharmacodynamic approach was used to predict clinical efficacy and to minimise the risk for selection of resistant bacteria (McKellar et al., 2004). The measured serum concentrations of doxycycline in both groups of chickens were twice as high than MIC value $(0.25 \mu \mathrm{g} / \mathrm{mL}) 2 \mathrm{~h}$ after the start of drug administration. They were still higher but close to MIC in broth $2 \mathrm{~h}$ after the end of the treatment. $\mathrm{Pk} / \mathrm{Pd}$ analysis shows that the calculated indices exceeded the breakpoints values, ensured clinical cure and minimised the risk of resistance in our experimental conditions. Probiotics treatment did not change $\mathrm{Pk} / \mathrm{Pd}$ indices indicating that adjustment of dosage after feed supplementation with Lactobacillus probiotic strains was not necessary.
In conclusion, probiotic treatment provoked no statistically significant differences in serum concentrations vs the doxycycline only treated group. The simultaneous treatment of chickens with probiotics and doxycycline did not require changes in the dose regimen. Significantly higher concentrations of doxycycline were detected in the liver of probiotic-treated animals. The same tendencies were found in the jejunum: the co-administration of probiotics and doxycycline resulted in higher concentrations of doxycycline, suggesting favourable results in the cure of bacterial diseases of poultry gastrointestinal tract. According to our experimental conditions no adjustment of dosage regimens of doxycycline, when combined with probiotics from the Lactobacillus spp. was necessary.

\section{ACKNOWLEDGMENTS}

The author wishes to thank Svetla Danova and Rositsa Tropcheva from The Stephan Angeloff Institute of Microbiology, Bulgarian Academy of Sciences (BAS) for providing the Lactobacillus strains from their collection and Nikolina Russenova from the Department of Microbiology, Infectious and Parasitic Diseases, Faculty of Veterinary Medicine, Trakia University for MIC values.

\section{REFERENCES}

Akbar, H., M. Khan, A. Ali Khan, M. Ali Khan, M. Shuaib, S. F. Akbar, S. Manzoor, Irshad-ur-rehman, S. Ahmad, L. Ali, R. Khalid \& M. Idrees, 2009. Comparative efficacy of doxycycline and flumequine against experimentally induced colibacillosis in broiler chicks. Journal of Veterinary Medicine and Animal Health, 1, 17-22.

Anadon, A., M. R. Martinez-Larranaga, M. J. Diaz, P. Bringas, M. A. Martinez, M. L. Fernandez-Cruz, M. C. Fernandez \& M. A. Martinez, 1994. Pharmacokinetics of 
doxycycline in broiler chickens. Avian Pathology, 23, 79-90.

Apata, D. F., 2008. Growth performance, nutrient digestibility and immune response of broiler chicks fed diets supplemented with a culture of Lactobacillus bulgaricus. Journal of the Science of Food and Agriculture, 88, 1253-1258.

Ashayerizadeh, O., B. Dastar, F. Samadi, M. Khomeiri, A. Yamchi \& S. Zerehdaran, 2014. Comparison between the effects of two multi-strain probiotics and antibiotic on growth performance, carcass characteristics, gastrointestinal microbial population and serum biochemical values of broiler chickens. Scientific Journal of Animal Science, 3, 110-119.

Atef, M., S. A. H. Youssef, H. A. El-Eanna \& A. A. El-Maaz, 2002. Influence of aflatoxin $\mathrm{B} 1$ on the kinetic disposition, systemic bioavailability and tissue residues of doxycycline in chickens. British Poultry Science, 43, 528-532.

Baert, K., S. Croubels, F. Gasthuys, J. De Busser \& P. De Backer, 2000. Pharmacokinetics and oral bioavailability of a doxycycline formulation (DOXYCYCLINE 75\%) in nonfasted young pigs. Journal of Veterinary Pharmacology and Therapeutics, 23, 45-48.

Burch, D. G. S. \& M. Valks, 2002. Comparison of minimal inhibitory concentrations (MIC) against chicken mycoplasma of tiamulin and other antimicrobials and their concentrations in the blood. Presentation at the World Veterinary Poultry Association, Cairo, Egypt, p. 322

Butaye, P., R. Ducatelle, P. De Backer, H. Vermeersch, J. P. Remon, \& F. Haeserbrouck, 1997. In vitro activities of doxycycline and enrofloxacin against european Chlamydia psittaci strains form turkeys. Antimicrobial Agents and Chemotherapy, 41, 2800-2801.

Cars, O. \& M. Ryan, 1988. Concentrations of doxycycline in muscle tissue and muscle tissue fluid. Scandinavian Journal of Infectious Diseases, 53 (Suppl.), 18-27.
Choi, J. Y., J. S. Kim, S. L. Ingale, K. H. Kim, P. L. Shinde, I. K. Kwon \& B. J. Chae, 2011. Effect of potential multimicrobe probiotic product processed by high drying temperature and antibiotic on performance of weanling pigs. Journal of Animal Science, 89, 1795-1804.

Cristina, R. T., I. Schmerold, E. Dumitrescu, C. Lazarescu, S. Petrovici \& A. Netotea 2010. Study of doxycycline efficacy in broiler's colibacilosis. Animal Science and Biotechnologies, 43, 469-473.

Danova, S., R. Tropcheva, N. Ivanovska, R. Georgieva, G. Dobreva-Yosifova, M. Petrova, P. Koleva, J. Dermendzjieva \& S. Dimitonova, 2012. Characterisation of Bulgarian lactobacilli as probiotics. In: Jubilee book: New Trends in Microbiology, ed A. Gulubov, $65^{\text {th }}$ Anniversary of the Stephan Angeloff Institute of Microbiology, Sofia, pp. 177-192.

Denli, M., F. Okan \& K. Celik, 2003. Effect of dietary probiotic, organic acid and antibiotic supplementation to diets on broiler performance and carcass yield. Pakistan Journal of Nutrition, 2, 89-91.

Doyle, M. P. \& M. C. Erickson, 2006. Reducing the carriage of foodborne pathogens in livestock and poultry. Poultry Science, 85, 960-973.

Edens, F. W., 2003. An alternative for antibiotic use in poultry: Probiotics. Revista Brasileira de Ciência Avícola, 5, 2.

El-Gendi, A. Y. I., M. Atef, A.M. Amer, G. M. Kamel, 2010. Pharmacokinetic and tissue distribution of doxycycline in broiler chickens pretreated with either: Diclazuril or halofuginone. Food and Chemical Toxycology, 48, 3209-3214.

Espigol, C., C. Artigas, J. Palmada \& A. Pages, 1997. Serum levels of doxycycline during water treatment in poultry. Journal of Veterinary Pharmacology and Therapeutics, 20 (Suppl. 1), 181-218.

Ferket, P., 2004. Alternatives to antibiotics in poultry production: responses, practical experience and recommendations, Alltech's Annual Symposium, http://en.engor- 
Effect of probiotics on doxycycline disposition in gastro-intestinal tract of poultry

mix.com/MA-poultry-industry/articles/alternatives-antibiotics-poultry-productiont405/p0.htm (17 April 2015 date last accessed).

Griggs, J. P. \& J. P. Jacobs, 2005. Alternatives to antibiotics for organic poultry production. The Journal of Applied Poultry Research, 14, 750-756.

Hantash, T. M., E. A. Abu-Basha, D. A. Roussan \& M. Abudabos, 2008. Pharmacokinetics and bioequivalence of doxycycline (Providox ${ }^{\circledR}$ and Doxyvet $0-50 \mathrm{~S} \AA$ ) oral powder formulations in chickens. International Journal of Poultry Science, 7, 161164.

Huang, M. K., Y. J. Choi, R. Houde, J. W. Lee, B. Lee \& X. Zhao, 2004. Effects of lactobacilli and an acidophilic fungus on the production performance and immune responses in broiler chickens. Poultry Science, 83, 788-795.

Kabir, S. M., 2009. The role of probiotics in the poultry industry. International Journal of Molecular Sciences, 10, 3531-3546.

Laczay, P., J. Semjen, J. Lehel \& G. Nagy, 2001. Pharmacokinetics and bioavailability of doxycycline in fasted and nonfasted broiler chickens. Acta Veterinaria Hungarica, 49, 31-37.

McKellar, Q. A., S. F. Sanchez Bruni \& D. G. Jones, 2004. Pharmacokinetic/ pharmacodynamic relationships of antimicrobial drugs used in veterinary medicine. Journal of Veterinary Pharmacology and Therapeutics, 27, 503-514.

Miranda, J. M., B. I. Vazquez, C. A. Fente, J. Barros-Velazquez, A. Cepeda \& C. M. Franco, 2008. Evolution of resistance in poultry intestinal Escherichia coli during three commonly used antimicrobial therapeutic treatments in poultry. Poultry Science, 87, 1643-1648.

Modesto, M., M. R. D'Aimmo, I. Stefanini, P. Trevisi, S. de Filippi, L Casini, M. Mazzoni, P. Bosi \& B. Biavati, 2009. A novel strategy to select Bifidobacterium strains and prebiotics as natural growth promoters in newly weaned pigs. Livestock Science, 122, 248-258.

Mountzouris, K. C., P. Tsitrsikos, I. Palamidi, A. Arvaniti, M. Mohnl, G. Schatzmayr \& K. Fegeros, 2010. Effects of probiotic inclusion levels in broiler nutrition on growth performance, nutrient digestibility, plasma immunoglobulins and cecal microflora composition. Poultry Science, 89, 58-67.

Nikolaidou, K., F. Samanidou \& N. Papadoyannis, 2008. Development and validation of an HPLC method for the determination of seven tetracycline antibiotics residues in chicken muscle and egg yolk according to 2002/657/EC. Journal of Liquid Chromatography \& Related Technologies, 31, 2141-2158.

Santini, C., L. Baffoni, F. Gaggia, M. Granata, R. Gasbarri, D. Di Gioia \& B. Biavati, 2010. Characterization of probiotic strains: An application as feed additives in poultry against Campylobacter jejuni. International Journal of Food Microbiology 141, S98-S108.

Semjen, G., T. Magyar \& P. Laczay, 1998. Therapeutic efficacy of doxycycline against experimental Pasteurella multoci$\mathrm{da}$ infection in broiler chickens. Acta Veterinaria Hungarica, 46, 85-93.

Sharifi, S. D., A. Dibamehr, H. Lotfollahian \& B. Baurhoo, 2012. Effects of flavomycin and probiotic supplementation to diets containing different sources of fat on growth performance, intestinal morphology, apparent metabolizable energy, and fat digestibility in broiler chickens. Poultry Science, 91, 918-927.

Stojancevic, M., G. Bojic, H. Al Salami \& M. Mikov, 2013. The Influence of intestinal tract and probiotics on the fate of orally administered drugs. Current Issues in Molecular Biology, 16, 55-68.

Toutain, P. L., J. R. Del Castillo \& A. Bousquet-Melou, 2002. The pharmacokinetic-pharmacodynamics approach to a rational dosage regimen for antibiotics. Research in Veterinary Science, 73, 105-114. 
Yang, F., G. H. Li, X. B. Meng, L. Wang, X. H. Huang, Q. Shan, D. P. Zeng, H. Z. Ding \& Z. L. Zeng, 2012. Pharmacokinetic interactions of flunixin meglumine and doxycycline in broiler chickens. Journal of Veterinary Pharmacology and Theraupeutics, 36, 85-88.

Paper received 10.01.2015; accepted for publication 13.03.2015

\section{Correspondence:}

Ivelina Pavlova Hristova DVM

Department of Pharmacology, Veterinary

Physiology and Physiological Chemistry,

Faculty of Veterinary Medicine,

Trakia University,

6000 Stara Zagora, Bulgaria,

e-mail: ivelpp@abv.bg 